\title{
СТРУКТУРНО-УРОВНЕВАЯ ОРГАНИЗАЦИЯ ВРЕМЕННОЙ ПЕРСПЕКТИВЫ ЛИЧНОСТИ ПАЦИЕНТОВ С ОНКОГЕМАТОЛОГИЧЕСКИМИ ЗАБОЛЕВАНИЯМИ
}

\author{
(С) Клюева Н.В. ${ }^{2}$, Никишина В.Б. ${ }^{1}$, Киселев И.Л. ${ }^{1}$, Хвостовой В.В. ${ }^{l}$, Петраш Е.А. ${ }^{l}$ \\ ${ }^{1}$ Курский государственный медицинский университет, Курск; \\ ${ }^{2}$ Ярославский государственный университет им. П.Г. Демидова, Ярославль \\ E-mail: petrash@mail.ru
}

\begin{abstract}
Реализовано эмпирическое исследование структурно-уровневой организации временной перспективы личности пациентов с онкогематологическими заболеваниями. Представлены результаты сравнительного анализа временной перспективы личности пациентов с онкогематологическими заболеваниями и с гематологическими заболеваниями в параметрах соотношения структурных компонентов (прошлого, настоящего, будущего), протяженности, временных установок. В результате исследования выявлено, что основным элементом временной перспективы личности пациентов с онкогематологическими заболеваниями является фаталистическое настоящее, диссоциированное как с будущим, так и с позитивным прошлым. При этом негативное прошлое, являясь источником поддержания переживаний фаталистического настоящего, не диссоциировано. Практическая значимость результатов заключается в том, что интегрированность будущего в структуру временной перспективы личности пациентов с онкогематологическими заболеваниями позволит активировать продуктивные механизмы преодоления заболевания, что является прогностически значимым в субъективном отношении к собственной болезни.
\end{abstract}

Ключевые слова: временная перспектива личности, онкогематологические заболевания, диссоциация.

\section{STRUCTURALLY-LEVEL ORGANIZATION OF PERSONAL TIME PERSPECTIVE IN PATIENTS WITH HEMATOLOGIC CANCERS}

Klyueva N.V. ${ }^{2}$, Nikishina V.B. ${ }^{l}$, Kiselev I.L. ${ }^{1}$, Khvostovoy V.V. ${ }^{l}$, Petrash E.A. ${ }^{l}$

${ }^{1}$ Kursk State Medical University, Kursk; ${ }^{2}$ P.G. Demidov Yaroslavl State University, Yaroslavl

The structurally-level organization of personal time perspective of patients with hematologic cancers has been empirically studied. The results of the comparative analysis of personal time perspective in patients with hematologic cancers and hematologic diseases are submitted in accordance with the correlations of the structural components (past, present, future), length, and time settings. According to the study the basic element of personal time perspective in patients with hematologic cancers is fatalistic present, dissociated both with the future and with the positive past. At the same time the negative past as a source of maintaining the fatalistic present experience is not dissociated. The practical significance of the results is that the integration of the future in the personal time perspective in patients with hematologic cancers will allow activating the productive coping mechanismsin response to the disease that is of prognostic significance in the subjective attitude to their own illness.

Keywords: time perspective of an individual, blood cancers, dissociation.

В последние 15 лет отмечается интенсивный прирост вновь зафиксированных случаев онкологического заболевания (за период 2001-2015 гг. увеличение количества вновь зафиксированных случаев онкологических заболеваний составило 1,4 раза) [17]. Учитывая высокие показатели смертности онкологических больных, переживание ситуации болезни данной нозологической группы сопровождается страхом смерти и ограничением жизни в субъективной картине. В связи с этим пациенты, страдающие онкологическими заболеваниями, не верят в благоприятный прогноз процессов лечения и реабилитации, что, в свою очередь, приводит к негативному настрою пациентов и, как следствие, снижению эффективности лечебно-реабилитационных мероприятий. Возникает необходимость определения путей активизации продуктивных механизмов преодоления онкологического заболевания. Онкологическое заболевание изменяет параметры времен- ной перспективы личности, что, в свою очередь, оказывает прогностически значимое воздействие на общее отношение к болезни, тем самым активируя продуктивные механизмы преодоления заболевания.

В современных научных исследованиях проблемы психологического времени можно выделить три основных направления: 1) типологическое направление, в рамках которого изучается, с одной стороны, специфика личностного времени людей, исходно разделенных на типы по каким-то иным основаниям; с другой - выделение разных типов отношения людей ко времени и затем возможное соотнесение этих типов с личностными особенностями; 2) причинно-целевое направление рассматривает личностную организацию времени, а также факторы, влияющие на особенности организации и соотношения структурных компонентов временной перспективы личности (прошлого, настоящего, будущего); 3) когнитивно-мотивационное направление, в рамках которо- 
го основной акцент сосредоточен на интенциональности человека, его стремлении предвосхищать будущие события или целевые объекты.

Осуществляя тематическое секторирование в рамках библиометрического анализа по ключевым словам «временная перспектива» на базе научной электронной библиотеки eLibrary, были выделены следующие направления научных исследований: временная перспектива в целом [8], временная перспектива будущего [16]; онтогенетические аспекты временной перспективы $[2,3$, $18]$; временная перспектива личности $[10,5]$.

По результатам проведенного тематического анализа исследований временной перспективы установлено, что клинико-психологический аспект изучения временной перспективы личности фактически не представлен, тогда как ситуация болезни, особенно онкологической, и по объективным, и по субъективным основаниям влияет на структуру и содержание временной перспективы.

Согласно определению $\Phi$. Зимбардо и Дж. Бойд (2010), временная перспектива представляет собой «...отношение личности ко времени, и это процесс, при помощи которого длительный поток существования объединяется во временные категории, что помогает упорядочить нашу жизнь, структурировать ее и придать ей смысл» [6], которое отражает установки, убеждения и ценности, связанные со временем [4]. Активным субъектом, интегрирующим, организующим и координирующим время на различных уровнях регуляции, выступает личность [1]. Временная перспектива личности выступает в качестве интегрирующего феномена, обеспечивающего целостность личности $[6,8,9]$. Временная перспектива характеризуется ее протяженностью, структурированностью, событийной наполненностью, эмоционально-ценностным отношением и формирует в норме личностный ресурс. В ситуации болезни, особенно болезни с неблагоприятным прогнозом, в первую очередь, трансформируется система ценностно-смысловых приоритетов, организующих временную перспективу, которые качественно меняют ее структуру и протяженность. Возникающие изменения временной перспективы в ситуации болезни существенно влияют на eе исход и качество жизни человека.

Ориентируясь на концепцию диссоциации, предложенною A.M. Ludwig (1983), диссоциация рассматривается как системное рассогласование психических явлений и реализуется в следующих характеристиках: изменения критичности мышления; нарушение чувства времени; чувство потери контроля над поведением; изменения в эмоциональной экспрессии; изменения образа тела; нару- шения восприятия; изменения смысла или значимости актуальных ситуаций или ситуаций, имевших место в прошлом; чувство возрастной регрессии [15].

Онкологическое заболевание в клинической психологии рассматривается как кризисная и экстремальная ситуация, имеющая ряд специфических признаков: внезапность появления, отсутствие возможности контроля ситуации, стадийность протекания заболевания и реакций на него, разрушение ранее сложившейся картины мира. В ситуации онкологического заболевания нарушается сложившееся функционирование личности, что проявляется в невозможности реализации своих жизненных ценностей и целей в рамках прежней модели поведения. Согласно данным современных исследований, онкологические больные ощущают безысходность своего положения, которая блокирует привычное течение жизни; происходит фрустрация духовных потребностей; бесперспективность приводит к утрате субъективного смысла жизни, трансформации системы жизненных ценностей, переоценке жизненного пути [9].

Для онкогематологических заболеваний характерна системность поражения, что может приводить к поражению остальных органов и тканей. При отсутствии химиотерапии, которая является одним из основных методов лечения онкологических заболеваний, время от выявления заболевания до гибели больных часто составляет от 1 до 5 месяцев. Качество жизни онкогематологических больных определяется в первую очередь иммунной уязвимостью, в связи с чем большую часть времени пациенты вынуждены находиться в специализированных стационарных условиях (с целью избежать посторонних внешних инфекций).

В ситуации онкологического гематологического заболевания диссоциация, являясь критерием структурно-уровневой организованности временной перспективы личности, поддерживает ее дискретность, дезинтегрированность на уровне событийной организации прошлого, настоящего, будущего.

Целью исследования является изучение структурно-уровневой организации временной перспективы личности пациентов с онкогематологическими заболеваниями.

\section{МАТЕРИАЛЫ И МЕТОДЫ ИССЛЕДОВАНИЯ}

Исследование осуществлялось на базе ОБУЗ «Курский областной клинический онкологический диспансер». Общий объем выборки составил 100 человек в возрасте 46,4士5,96 года. В экспериментальную группу вошли 50 пациентов (37 муж- 
чин и 13 женщин) с онкогематологическим заболеванием (С91 «Лимфоидный лейкоз» по МКБ-10) с преимущественным поражением лимфатических узлов и костного мозга. Все пациенты экспериментальной группы получали цитостатическое лечение при систематическом контроле показателей гемограммы (1-2 раза в неделю). Контрольная группа включала в себя 50 пациентов с гематологическими заболеваниями (D50 «Железодефицитная анемия» по МКБ-10). На момент психодиагностического обследования пациенты экспериментальной и контрольной групп находились в состоянии ремиссии. Обследование осуществлялось в условиях стационара в индивидуальной форме на условиях информированного согласия.

Эмпирическое исследование осуществлялось с использованием следующих психодиагностических методик: методика «Линия жизни», опросник временной перспективы Ф. Зимбардо [6], опросник временных установок Ж. Нюттена [13], Шкала диссоциации (DES) в адаптации H.В. Тарабриной [15], опросник ценностей Ш. Шварца [7]. Количественная и качественная обработка полученных данных включала в себя методы описательной (гистограмма средних значений, стандартное отклонение), сравнительной (непараметрический U-критерий МаннаУитни) статистики, методы корреляционного (r-критерий ранговой корреляции Спирмена) и регрессионного анализов.

Организация эмпирического исследования осуществлялась последовательно в три этапа. Задачей первого этапа исследования являлось изучение временной перспективы личности пациентов с онкогематологическими заболеваниями в параметрах соотношения структурных компонентов (прошлого, настоящего, будущего), протяженности, временных установок. Вторым этапом исследования являлся структурно-содержательный анализ временной перспективы пациентов с онкогематологическими заболеваниями с использованием метода корреляционного анализа. На заключительном этапе исследования осуществлялась оценка вектора влияния диссоциации на структурно-уровневую организацию временной перспективы личности пациентов с онкогематологическими заболеваниями с использованием метода регрессионного анализа.

\section{РЕЗУЛЬТАТЫ ИССЛЕДОВАНИЯ И ИХ ОБСУЖДЕНИЕ}

В результате исследования временной перспективы личности пациентов с онкогематологическими заболеваниями на уровне соотношения структурных компонентов временной перспекти- вы личности пациентов с онкологическими заболеваниями крови выявлено преобладание событий фаталистического настоящего $(\mathrm{x} \pm \sigma=3,51 \pm$ $0,54)$ и негативного прошлого $(\mathrm{x} \pm \sigma=3,41 \pm 0,61)$ при снижении гедонистического настоящего $(\mathrm{x} \pm \sigma=3,15 \pm 0,32)$. У пациентов с гематологическими заболеваниями временная перспектива личности характеризуется значимым $(\mathrm{p}=0,031)$ преобладанием событий фаталистического настоящего $(\mathrm{x} \pm \sigma=3,49 \pm 0,54)$ и позитивного прошлого $(\mathrm{x} \pm \sigma=3,66 \pm 0,72)$ при значимом снижении $(\mathrm{p}=0,024)$ негативного прошлого $(\mathrm{x} \pm \sigma=3,13 \pm 0,37)$ и гедонистического настоящего $(\mathrm{x} \pm \sigma=3,24 \pm 0,44)$. Фаталистическое настоящее у пациентов с онкогематологическими заболеваниями поддерживается содержанием негативного прошлого: события прошлого рассматриваются в качестве причин развития заболевания. У пациентов с гематологическими заболеваниями фаталистическое настоящее поддерживается позитивной оценкой своего прошлого: настоящее в ситуации болезни характеризуется фаталистичностью в сравнении с событийной наполненностью прошлого.

В графической форме соотношение структурных компонентов временной перспективы у пациентов с онкогематологическими заболеваниями и пациентов с гематологическими заболеваниями представлено в диаграммах долевого распределения на рис. 1.

На уровне протяженности у пациентов с онкогематологическими заболеваниями выявлена ограниченность временной перспективы событиями прошлого $(\mathrm{x} \pm \sigma=12,4 \pm 4,28)$, в то время как у пациентов с гематологическими заболеваниями протяженность временной перспективы личности $(\mathrm{x} \pm \sigma=14,31 \pm 5,46)$ характеризуется преобладанием настоящего и прошлого.

На уровне временных установок у пациентов с онкогематологическими заболеваниями выявлено преобладание установок на будущее $(\mathrm{x} \pm \sigma=$ $3,97 \pm 0,82)$ и прошлое $(x \pm \sigma=3,90 \pm 0,68)$. У пациентов с гематологическими заболеваниями в системе временных установок также преобладают установки будущего $(\mathrm{x} \pm \sigma=4,03 \pm 0,61)$ и прошлого $(\mathrm{x} \pm \sigma=3,94 \pm 0,61)$ при дефицитарности установок настоящего ( $\mathrm{x} \pm \sigma=3,86 \pm 0,61)$. При оценке значимости различий показателей временных установок выявлено значимое преобладание установок прошлого $(\mathrm{p}=0,024)$ и будущего $(\mathrm{p}=0,031)$ у пациентов с гематологическими заболеваниями в сравнении с пациентами с онкогематологическими заболеваниями (рис. 2).

Временная перспектива пациентов с онкогематологическими заболеваниями характеризуется ограниченностью протяженности преимущественно событиями негативного прошлого, так как 
Пациенты

с онкогематологическими заболеваниями

$21,20 \%$

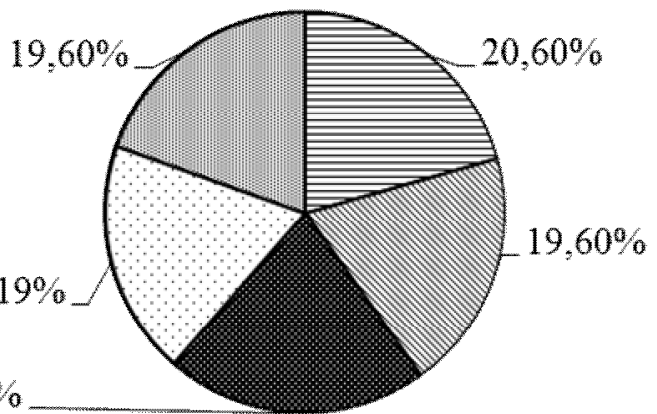

目Негативное прошлое

Позитивное прошлое

Фаталистическое настояшее

$\square$ Гедонистическое настоящее

๑ Будушее
Пациенты

с гематологическими заболеваниями

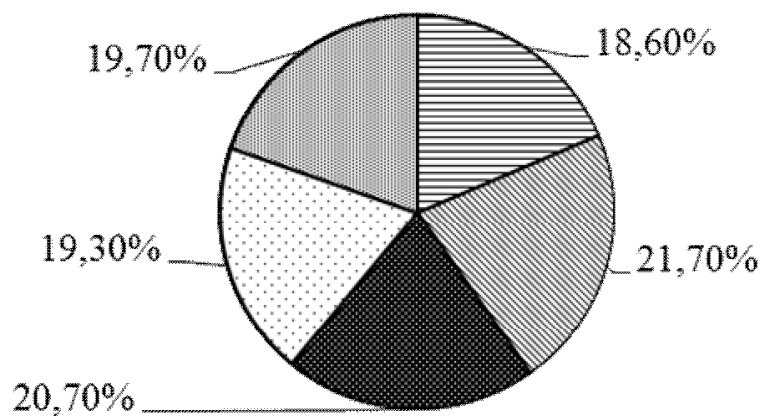

в Негативное прошлое

Позитивное прошлое

Фаталистическое настоящее

๑Гедонистическое настоящее

п. Будушее

Рис. 1. Диаграммы долевого распределения структурных компонентов временной перспективы личности пациентов с онкогематологическими заболеваниями и пациентов с гематологическими заболеваниями.

Пациенты

с онкогематологическими заболеваниями

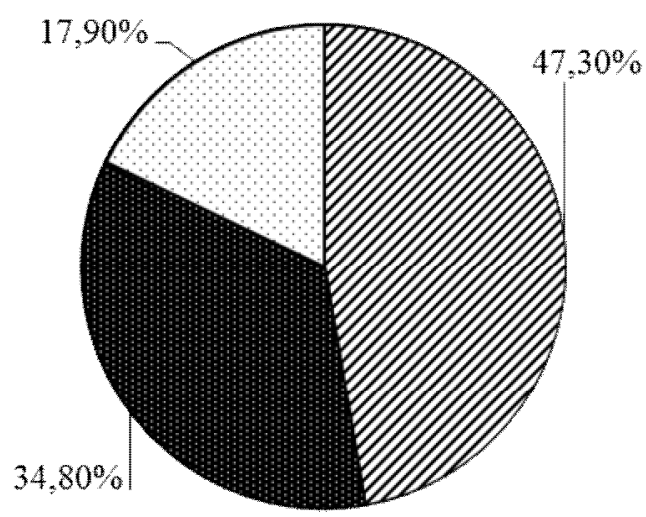

口Прошлое вастояшее ФБудущее
Пациенты

с гематологическими заболеваниями

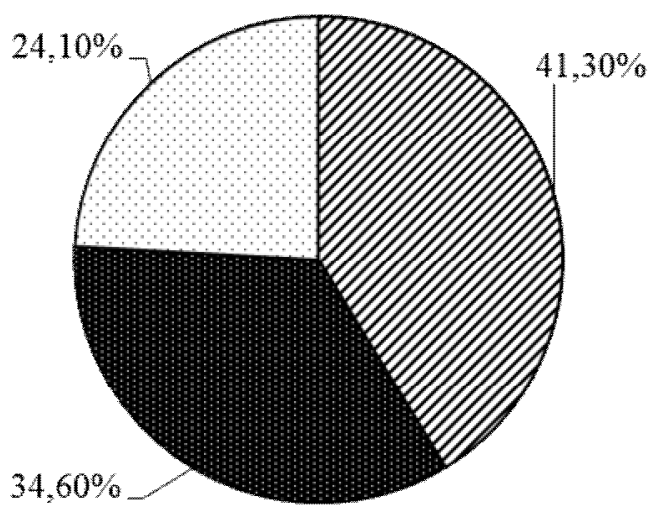

घПрошлое 由настоящее घБудушее

Рис. 2. Диаграммы долевого распределения временных установок пациентов с онкогематологическими заболеваниями и пациентов с гематологическими заболеваниями.

именно в прошлом больные находят причины своего заболевания. При этом настоящее оценивается как фаталистическое, основным содержанием которого является ситуация онкологического заболевания и процедура лечения. Снижение доли будущего в структуре временной перспективы личности, а также временных установок на будущее обусловлено высокими показателями смертности пациентов данной нозологической группы. У пациентов с гематологическими заболеваниями временная перспектива личности ограничена событиями позитивного прошлого и настоящего; имея предшествующий жизненный опыт вне ситуации болезни и сравнивая его с текущей ситуацией гематологического заболевания, требующей длительного лечения, события прошлого оцениваются как позитивные. Ситуация болезни рассматривается как фаталистическая, так как прогноз полного выздоровления в большинстве случаев оказывается неблагоприятным. Снижение выраженности временных установок на будущее также связано с необходимостью пожизненной поддерживающей терапии.

Содержание временной перспективы личности определяется и регулируется системой ценностных ориентаций. В результате исследования системы ценностных ориентаций у пациентов с онкогематологическими заболеваниями выявлено рассогласование системы ценностных ориентаций на уровне представлений и на уровне их реализации в поведении, которое проявляется в преобладании на уровне представлений ценностей добро- 
ты, универсализма и самостоятельности; на уровне поведения преобладающими являются ценности достижения и стимуляции (рис. 3).

В системе ценностных ориентаций онкогематологических больных на уровне нормативных идеалов, характеризующих ценностные ориентации на уровне представлений, значимо преобладают ценности универсализма $(\mathrm{p}=0,021)$, мотивационной целью которой являются понимание, терпимость, защита благополучия не только себя, но и своего социального окружения; ценности самостоятельности $(\mathrm{p}=0,037)$, проявляющиеся в самостоятельности мышления, способа действия, автономности и независимости; ценности доброты ( $\mathrm{p}=0,014)$, характеризующиеся доброжелательностью, стремлением к сохранению благополучия близких людей; и ценности безопасности $(p=0,025), \quad$ проявляющиеся в поддержании стабильности взаимоотношений для себя и других. На уровне индивидуальных приоритетов система ценностных ориентаций онкогематологических больных, отражающая ценностные ориентации, реализуемые в поведении, характеризуется значимым преобладанием ценностей достижений $(p=0,018)$, проявляющихся в социальной компетентности, реализуемой с целью социального одобрения; и ценности стимуляции ( $\mathrm{p}=0,021)$, проявляющихся в стремлении к новизне и глубоким переживаниям.

Система ценностных ориентаций гематологических больных также характеризуется рассогласованностью ценностей на уровне представлений и их реализацией в поведении. При этом на уровне представлений значимо преобладают ценности доброты $(\mathrm{p}=0,034)$, универсализма $(\mathrm{p}=0,040)$ и традиций $(\mathrm{p}=0,013)$, которые проявляются в уважении и принятии социальных норм и традиций, проявлении доброжелательности во взаимодействии с близкими, проявлении понимания и терпимости.

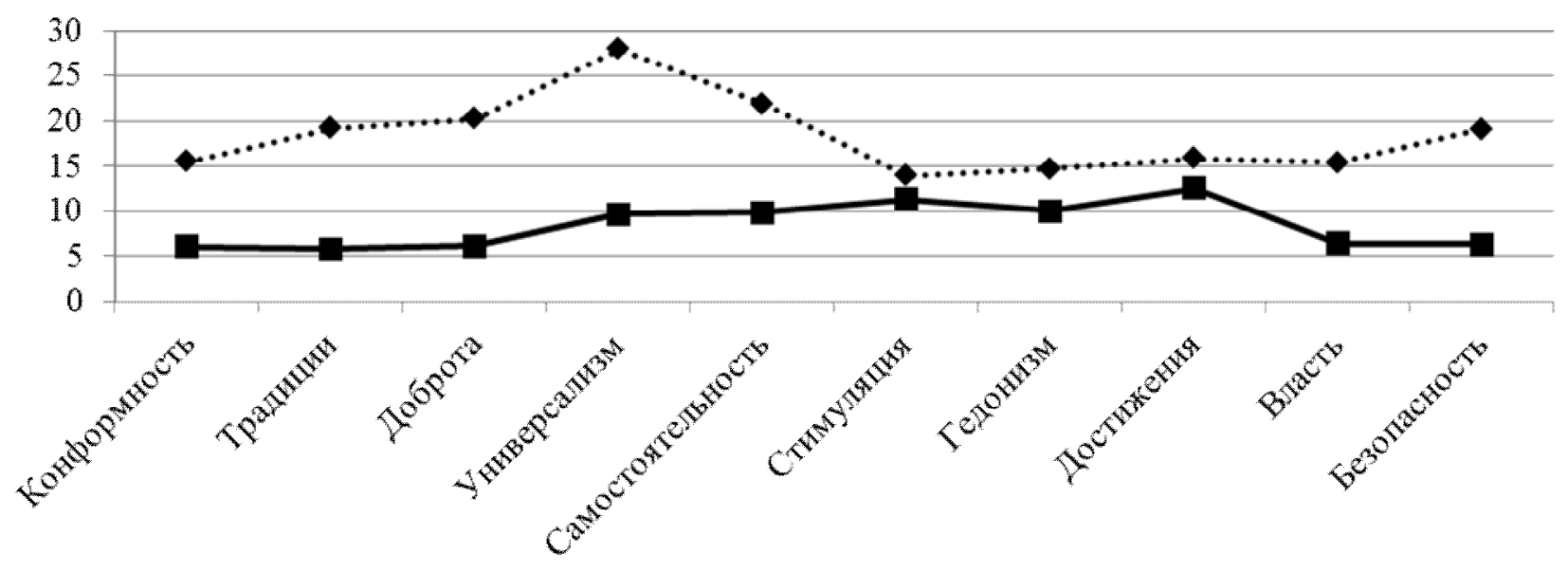

$\cdots \bullet \cdot$ Обзор ценностей $\rightarrow-$ Профиль ценностей

Рис. 3. Усредненный профиль системы ценностных ориентаций пациентов с онкогематологическими заболеваниями.

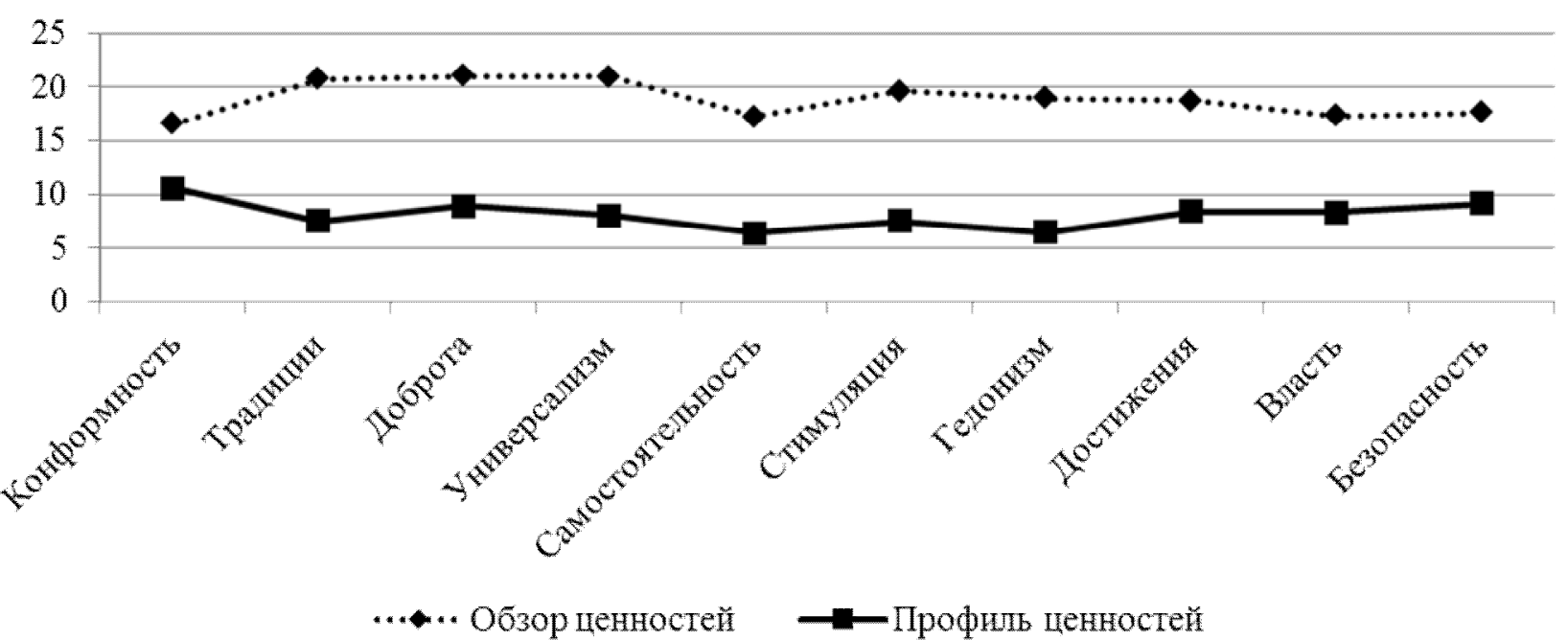

Рис. 4. Усредненный профиль системы ценностных ориентаций гематологических больных. 
На уровне реализации в поведении значимо преобладают ценности конформности $(\mathrm{p}=0,004)$, безопасности $(\mathrm{p}=0,014)$ и доброты $(\mathrm{p}=0,021)$, что проявляется в доброжелательности, поддержании стабильности и безопасности во взаимодействии с близкими, а также сдерживании и предотвращении действий, которые могут причинить вред другим или не соответствуют социальным ожиданиям (рис. 4).

В результате исследования системы ценностных ориентаций онкогематологических больных выявлено противоречие: содержание системы ценностей на уровне представлений не соответствует реализуемым; понимание, терпимость и защита благополучия, самостоятельность и независимость, а также стремление к поддержанию стабильности взаимоотношений являются декларативными; в условиях реального взаимодействия пациенты демонстрируют социальную компетентность, реализуемую с целью получения социального одобрения, а также глубокую погруженность в собственные переживания.

В результате структурно-содержательного анализа временной перспективы пациентов с онкогематологическими заболеваниями с использованием метода корреляционного анализа (r-критерий ранговой корреляции Спирмена, $\mathrm{p}<0,05)$ параметров временной перспективы личности и ценностных ориентаций выявлены прямо пропорциональные статистически значимые взаимосвязи между ценностями достижений и будущим $(\mathrm{r}=0,47)$; обратно пропорциональные статистически значимые взаимосвязи между ценностями универсализма и будущего $(\mathrm{r}=-0,62)$, фаталистическим настоящим и ценностями стимуляции ( $\mathrm{r}=-$ $0,38)$, достижения $(\mathrm{r}=-0,54)$ и доброты $(\mathrm{r}=-0,39)$. Полученные результаты корреляционного анализа указывают на то, что содержание временной перспективы личности пациентов с онкогематологическими заболеваниями реализуется через ценности универсализма, стимуляции, достижений и доброты.

$\mathrm{y}$ пациентов с гематологическими заболеваниями прямо пропорциональные статистически значимые взаимосвязи выявлены между ценностями доброты и показателями будущего $(\mathrm{r}=0,44)$, а также ценностями самостоятельности и показателями негативного прошлого $(\mathrm{r}=0,37)$; обратно пропорциональные статистически значимые взаимосвязи выявлены между показателями фаталистического настоящего с ценностями традиций $(\mathrm{r}=-$ $0,48)$ и гедонизма $(\mathrm{r}=-0,56)$. Содержание временной перспективы личности пациентов с гематологическими заболеваниями реализуется в ценностях традиций, гедонизма, самостоятельности и доброты.
В качестве критерия структурно-уровневой организованности временной перспективы личности пациентов с онкогематологическими заболеваниями выступает показатель диссоциации. В связи с этим осуществлялась оценка вектора влияния диссоциации на структурно-уровневую организацию временной перспективы личности пациентов с онкогематологическими заболеваниями с использованием метода множественного регрессионного анализа.

В результате исследования уровня диссоциации у пациентов с онкогематологическими заболеваниями выявлен высокий уровень диссоциации $(\mathrm{x} \pm \sigma=0,57 \pm 0,34)$, в то время как у пациентов с гематологическими заболеваниями уровень диссоциации соответствует диапазону средних значений $(\mathrm{x} \pm \sigma=0,24 \pm 0,09)$. Согласно результатам проведенного множественного регрессионного анализа (обратного пошагового метода) установлено, что временная перспектива пациентов с онкогематологическими заболеваниями диссоциируется на уровне позитивного прошлого $(\beta=-0,557$; $\mathrm{p}=0,042)$, будущего $(\beta=1,204 ; \mathrm{p}=0,018)$, а также временных установок на будущее $(\beta=-1,051$; $\mathrm{p}=0,015)$.

Основным элементом временной перспективы личности пациентов с онкогематологическими заболеваниями является фаталистическое настоящее, которое диссоциируется как с будущим, так и с позитивным прошлым; негативное прошлое, являясь источником поддержания переживаний фаталистического настоящего, не диссоциируется.

Практическая значимость полученных результатов исследования заключается в том, что увеличение доли будущего, его интегрированности в структуру временной перспективы личности пациентов с онкогематологическими заболеваниями позволит целенаправленно формировать продуктивные установки на преодоление безысходности и бесперспективности, что является прогностически значимым в субъективном отношении к собственной болезни. Прогностически благоприятный прогноз лечения формируется, в том числе, на основании субъективного отношения пациентов с лимфоидным лейкозом к процессу лечения, к болезни, которое встроено в систему общей траектории временной перспективы, содержащей в части будущего когнитивный, эмоциональный, волевой потенциал совладания с болезнью.

\section{ЛИТЕРАТУРА}

1. Абульханова К.А., Березина Т.Н. Время личности и время жизни. - СПб. : Алетейя, 2001. - 304 с. 
2. Авдулова Т.П. Структура идентичности и временная перспектива дошкольников // Психология обучения. - 2009. - № 11. - С. 57-69.

3. Быльченко М.В. Особенности формирования идентичности в юношеском возрасте [Электронный ресурс] // Психологические исследования: электрон. науч. журн. - 2009. № 4 (6). - Режим доступа: http://psystudy.ru, свободный (10.06.2015 г.).

4. Головаха Е.И., Кроник А.А. Психологическое время личности. - Киев : Наукова Думка, 1984. - 130 с.

5. Демина Л.Д., Смирнова Я.К. Особенности проявления временной перспективы при разной уровневой организации психологической суверенности личности // Известия Алтайского государственного университета. - 2013. - Т. 2, № 2 (78) - C. 56-59.

6. Зимбардо Ф., Бойд Дж. Парадокс времени. Новая психология времени, которая улучшит вашу жизнь. - СПб. : Речь, 2010. - С. 60-68.

7. Карандашев В.Н. Методика Шварца для изучения ценностей личности: концепция и методическое руководство. - СПб. : Речь, 2004. - 72 с.

8. Кравченко Л.В. Событие как единица анализа психологического времени // Известия Волгоградского государственного педагогического университета. - 2008. - № 4. - С. 8-12.

9. Липецкий Н.Н. Психологические особенности отношения к жизни онкологических больных (на примере женщин больных раком молочной железы III ст.) // Молодой ученый. - 2013. - № 7 . C. 372-374.

10. Лобанова Е.С., Михайлова А.А. Особенности временной перспективы личности осужденных мужчин, имеющих наркотическую зависимость // Вестник института: преступление, наказание, исправление. - 2010. - № 9. - С. 54-57.
11. Максименко С.Д. Основы генетической психологии: уч. пос. - Киев : НПЦ Перспектива, 1998. $-220 \mathrm{c}$.

12. Максименко С.Д. Генезис существования личности. - Киев : Издательство ООО «КММ», $2006-240 \mathrm{c}$.

13. Максименко С.Д., Максименко К.С., Никишина В.Б., Петраш Е.А., Кузнеизова А.А. Ассоциативно-диссоциативные механизмы временной перспективы личности при алкогольной зависимости // Курский научнопрактический вестник «Человек и его здоровье». 2014. - № 1. - С. 85-91.

14. Нюттен Ж. Мотивация, действие и перспектива будущего / Под ред. Д.А. Леонтьева. - М. : Смысл, 2004. $-608 \mathrm{c}$.

15. Тарабрина Н.В., Агарков В.А., Быховец Ю.В., Калмыкова Е.С., Макарчук А.В., Падун М.А., Удачина Е.Г., Химчян З.Г., Шаталова Н.Е., Щепина А.И. Практическое руководство по психологии посттравматического стресса. Ч. 1. Теория и методы. - М. : Изд-во «Когито-Центр», 2007. -208 c.

16. Tолстых Н.Н. Хронотоп: культура и онтогенез. Смоленск-Москва : Универсум, 2010. - 292 с.

17. Федеральная служба государственной статистики. Раздел: Заболеваемость населения по основным классам болезней Официальный сайт. - URL: http://www.gks.ru/wps/wcm/connect/rosstat_main/ros stat/ru/statistics/population/healthcare/\#

18. Яницкий М.С., Серый А.В., Проконич О.А. Особенности временной перспективы личности представителей различных ценностных типов массового сознания // Вестник КРАУНЦ. Гуманитарные науки. - 2012. - № 2 (20). C. $175-180$. 